\section{SINIPAK COSTUME OF THE DUSUN TINDAL WOMEN FOLK OF SABAH}

\author{
Noria ak Tugang \\ Universiti Malaysia Sarawak
}

\section{Salbiah Kindoyop}

Universiti Malaysia Sarawak

\section{Junior Kimwah}

Universiti Malaysia Sarawak

\section{Nurul Aisyah Othman \\ Universiti Malaysia Sabah}

Corresponding Author tnoria@unimas.my
The sinipak traditional costumery is a centuriesold heritage inherited by the Dusun Tindal ethnic community located mainly in the flatlands of Kampung Bangkahak, Kampung Tempasuk and Kampung Piasau in the Kota Belud district of Sabah, Malaysia. The designs and accessories exhibited in the sinipak costume of the Dusun Tindal womenfolk are representative of natural materials and elements integrated with human creativity, and are traditionally perceived as symbols of wealth and social status within the community. Findings of this study were derived from fieldwork data and analysis of the design concepts of the sinipak female costumery.

Keywords: Dusun Tindal, design, sinipak, costume, and accessories 


\section{INTRODUCTION}

An ethnic group or community could be identified through the culture that the people in that grouping practise such as their traditional costumes, dances, and language or dialect spoken. For the Dusun Tindal, their traditional costumery is one of the most distinctive and unique attributes of their heritage. These ornate costumes, rich in traditional adornment and steeped in cultural significance, are commonly donned during festivities and important events such as weddings, welcoming of visitors, and other social events.

The Dusun Tindal ethnic has two types of traditional costumes known as sinipak and rinagang. These two types of costumes were recorded by I.H.N Evans in year 1953 and John White in 1893. Recorded images of both traditional costumes in the form of photographs proved their existence in the history of Dusun Tindal ethnic. Changes in costume designs can also be seen from time to time until today. The sinipak costumes are worn by Dusun Tindal ethnic who lived in flat area while the rinagang costumes are worn by Dusun Tindal ethnic lived on the hillside.

The focus of this study is the sinipak costumes, which have a design dominated in black colour and decorated with red dastar [Table 1 (i)]. According to informant 1 (Pahau, personal communication, Feb 4, 2016) due to the time transition, these costumes are decorated by attractive accessories and beads embroidery to make them more attractive [Table 1 (ii)]. Among the transformation are the changes in the size of the embroidery dastar fabric, the geometric motifs were embroidered with smaller size and more attractive. Today's costume design is more complex with the use of more comfortable fabrics and the addition of the embroidery motifs to the sinipak costume [Table 1 (iii)].

\section{BACKGROUND}

The traditional costumery of the Dusun Tindal consists of the sinipak, rinagang and sinuranga. All three are black in colour and would usually be embellished with colourful embroidery patterns, motifs or decorations. The sinipak itself has male and female versions; this study examines specifically the sinipak for womenfolk in terms of its functions and accompanying accessories.

\section{METHODOLOGY}

Photography is used in practice-based research or other research situations or environments for the acquisition of visual data, storage or management of visual 
information, analysis of visual data, and the presentation of research findings. Visualisation requires drawing in all forms (for instance objective, analytical, or expressive), diagrams, concept maps or mind maps, flow charts, storyboards, matrices, and network displays by employing colour, tone line, plane, shape, scale, symbol, and so on. The use of metaphors and analogy could also stimulate or assist this visualisation process. The interview method is useful as it presents a key pathway in seeking the particular opinions of others about identified research topics. A purposeful conversation is initiated by the interviewer and focused by him or her on content specified by his research objectives. Data for this study was documented via notes, photography, sketches and voice recorder. This technique enabled the researchers to experience a critical visual understanding of cultural practices based on the interviews and observation.

\section{DISCUSSION OF FINDINGS}

\subsection{Sinipak costumery}

The sinipak is synonymous to the Dusun Tindal of Kota Belud. The uniqueness of sinipak lies in the intricate embroidery that forms the motifs and patterns on the costume. These ornate embellishments reflecting elements of nature, culture and traditional life are indicative of the Dusun Tindal expertise in traditional costume tailoring and embroidery; in fact, so refined and renowned is this skill that it indirectly offers a lucrative income since a well- made sinipak could command a very high price in the open market.

Sinipak-making is a laborious and complicated process that requires expensive materials. This time- factor aspect and the cultural identity value ascribed to the costume render the sinipak in its entirety an expensive piece of workmanship often out-of-the economic reach of many people in the community. This has led to a common situation whereby costume makers would often assemble a collection then make these available for short-term rentals for occasions such as weddings and festivals.

Table 1: Images of Sinipak Costumery

\begin{tabular}{|c|l|}
\hline i. Sinipak in 1938 & $\begin{array}{l}\text { This image recorded in 1938 by I.H.N. Evans } \\
\text { shows the wedding costume finery of Gintuak (left) } \\
\text { from the Dusun Tindal of Kg. Kadamaian with his } \\
\text { wife (right), a Dusun Tobilung from Kg. Toburon. } \\
\text { The groom donned accessories such as the sigar } \\
\text { (headgear), tinggot (belt), and lolopot (mantle). The }\end{array}$ \\
\hline
\end{tabular}




\begin{tabular}{|c|c|}
\hline & $\begin{array}{l}\text { betewi buttons decorated the chest and sleeve } \\
\text { areas of the sinipak. }\end{array}$ \\
\hline ii. & $\begin{array}{l}\text { Black colour material coupled with a red mantle } \\
\text { were predominant in the original sinipak costume. } \\
\text { However, with the advent of time and due to a clash } \\
\text { of culture, the costume gradually evolved into a } \\
\text { form of costumery complemented with accessories } \\
\text { and bead embroidery. }\end{array}$ \\
\hline iii. Sinipak in 2016 & $\begin{array}{l}\text { The sinipak textile, original produced using } \\
\text { traditional methods, were often long lasting. } \\
\text { Traditional fabric makers however are no longer } \\
\text { found. } \\
\text { The modern version of the sinipak base fabric is } \\
\text { black velvet textile since this material is easy to find } \\
\text { and commercially available. The beads and betewi } \\
\text { buttons are embroidered or sewn at the chest and } \\
\text { sleeve areas. The linangkit is also embroidered on } \\
\text { the sleeves just before the folding part of the elbow. } \\
\text { The accessory usage however remains } \\
\text { unchanged, the only difference being these are } \\
\text { now mostly mass- produced ornaments and no } \\
\text { longer the authentic hand-wrought versions of the } \\
\text { olden days. }\end{array}$ \\
\hline
\end{tabular}

Table 1 (i-iii) show images of the sinipak costume as worn by wedding couples over three different time periods. From the three pictures, it is clear that the sinipak has evolved over time in terms of design and accessories with the most obvious change being the addition of bead embroidery and linangkit motifs. However, these additions or changes in design are still incorporated with reference to the original design of the Dusun Tindal costumery.

\subsection{Decorations on sinipak for women}

The complete ensemble of the sinipak costume and accessories for Dusun Tindal women consists of eleven elements namely lolopot, kuapu, sinipak, saring, pirok, solindang, tinggot, baratina, babagas, gonob and lungkaki. The accessories worn by 
the womenfolk are more elaborate as compared to the version for men although both share similarities in design, colour, decoration, and bead motif embroidery. According to an informant, the wearing of the sinipak during traditional ceremonies and social events is an integral aspect of the Dusun Tindal culture. In marriage ceremonies for instance, the wedding parties from both groom and bride sides as well as festivity dancers are required to be dressed in the sinipak. For the bride and groom, the sinipak has to be in its entire or complete set. The wearing of this costume is intended to make the couple look resplendent and regal, and simultaneously add to the richness and significance of the marriage event.

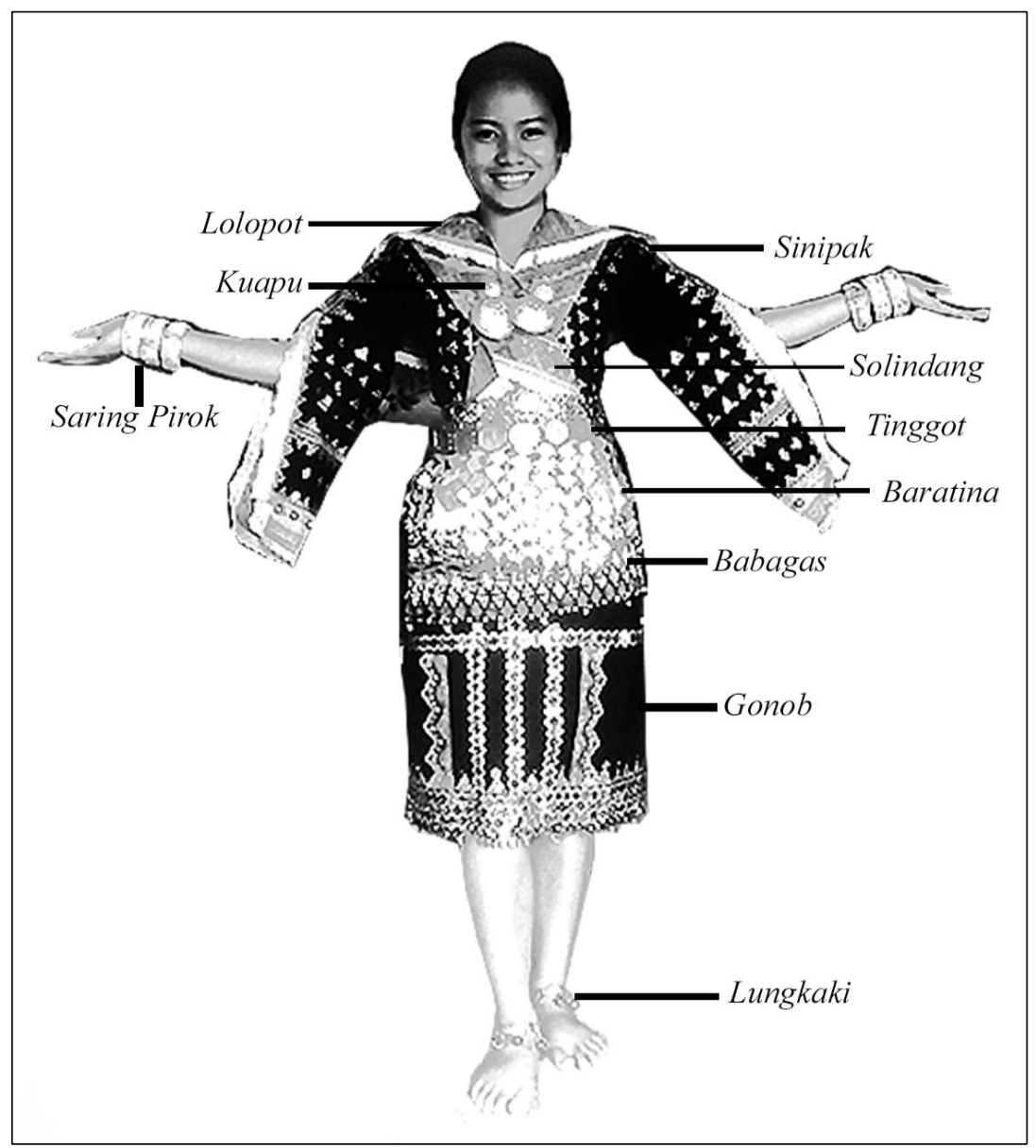

Figure 1: Pictorial Description of Sinipak for Women 
Table 2: Complete sinipak costumery for women

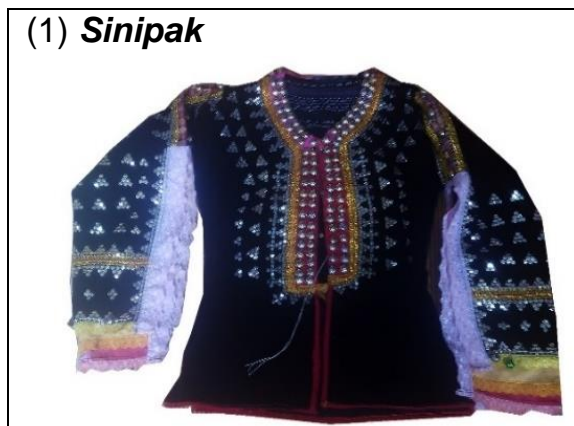

The long sleeve black cloth is of baldu (velvet) material. The elbow area has the colours red, yellow and green. The upper part of the sleeve is decorated with linangkit motif golden lace. Golden betawi buttons adorn the front part and along the elbow area of the sinipak.

(3) Lolopot

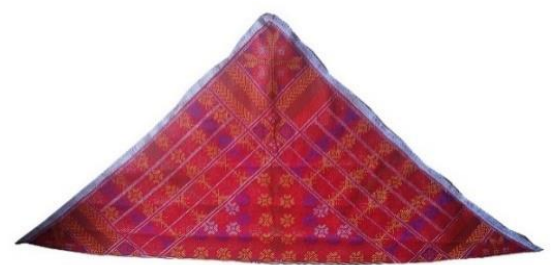

The mantle is folded sideways onto the chest and tied at the waist. Red colour thread is woven alongside motifs in geometrical shapes such as triangles and squares.

\section{(5) Sunduk}

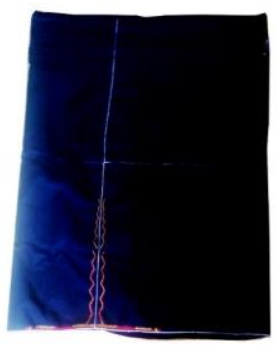

On this black cloth embroidered with red and yellow coloured threads, beads are arranged in horizontal and vertical positions.

\section{(2) Gonob}

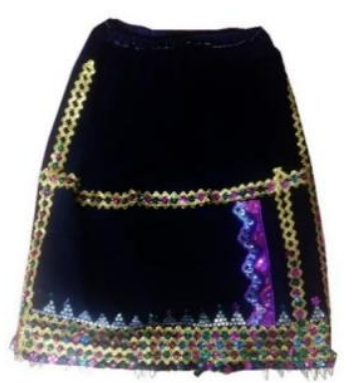

The knee- length black skirt is embroidered with threads in the colour red, yellow, white, and green. The embroidery patterns are in zig-zag formation with linangkit motifs. Golden colour lace is embroidered in upright and horizontal lines on the skirt front.

(4) Solindang

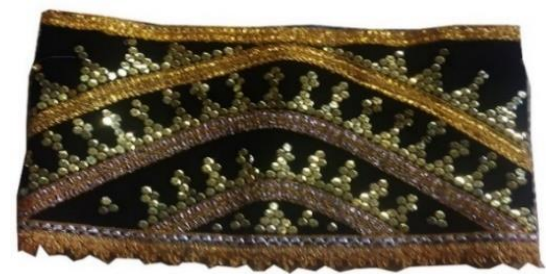

This is black in colour and embellished with gold coloured beads with geometrical motif decorations.

(6) Kuapu

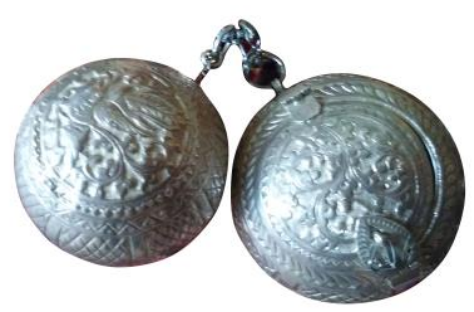

This is a spherical shaped silver tobacco case worn necklace-style. Two or three pieces would be put on by the wearer at any one time. The engraved motifs are usually floral. 
(7) Baratina

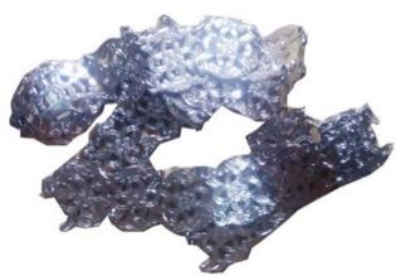

The belt is made from silver-coloured metal and arranged like chains.
(8) Saring pirok

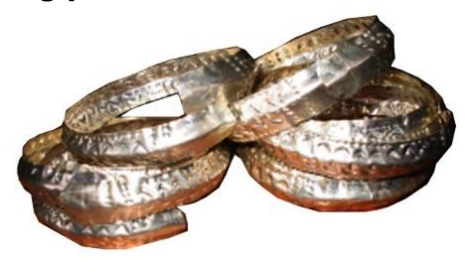

The silver bangles are made in triangular and round shapes with patterns engraved onto the outer face.

(9) Tinggot

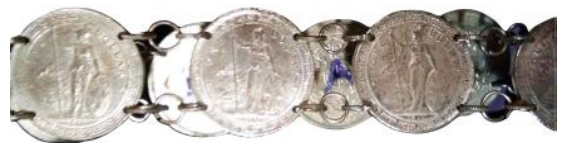

Made of silver coins (Hong Kong dollar coins showing the relief of the Dutch Queen Wilheminia) forged together, the belt is worn below the baratina. The number of belts adorning the wearer reflects his wealth or social status; the more strands there are, the richer his family background or the higher his social standing.

(10) Babagas

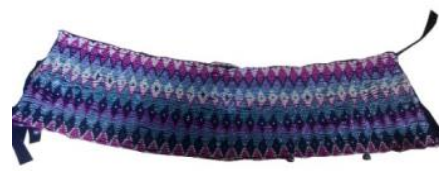

A woven bead arrangement specifically to 'sit' on the hip area. At six inches wide, the bead hip adornment is understandably heavy.

\section{(11) Lungkaki}

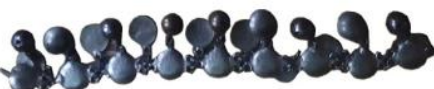

The foot bangles are silver in colour with similar engraved motifs as those on the saring pirok.

Table 2 presents the complete sinipak costumery for Dusun Tindal womenfolk. The wearing of the sinipak is layered with a shirt and skirt known as sinipak and gonob. The lolopot, kuapu, saring pirok, solindang, tinggot, baratina, babagas and lungkaki accessories are ornamental decorations that complement and complete the sinipak costume for Dusun Tindal womenfolk. 


\subsection{SINIPAK DESIGN}

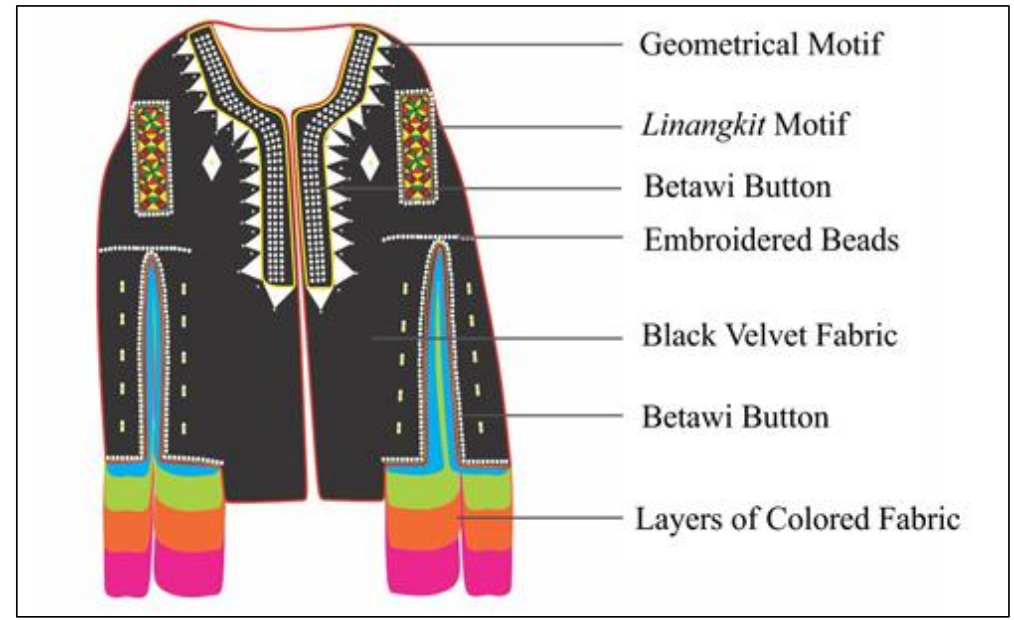

Figure 2: Sinipak costume

The sinipak costume for men and women share similarities in terms of design and motif. The colourful laces arranged in layers on the sleeve cut out is dominant in the overall outlook. The betewi buttons located at the chest and elbow area have a unique design and reflect the identity of the sinipak. Silver beads are embroidered in a triangular shape on the chest area and behind the sinipak. The linangkit embroidery on both upper arm area of the costume represents the status of the individual with the choice of embroidery colour and number of colour representative of his or her status symbol - the more colours there are, the higher that person or his family's standing in the community.

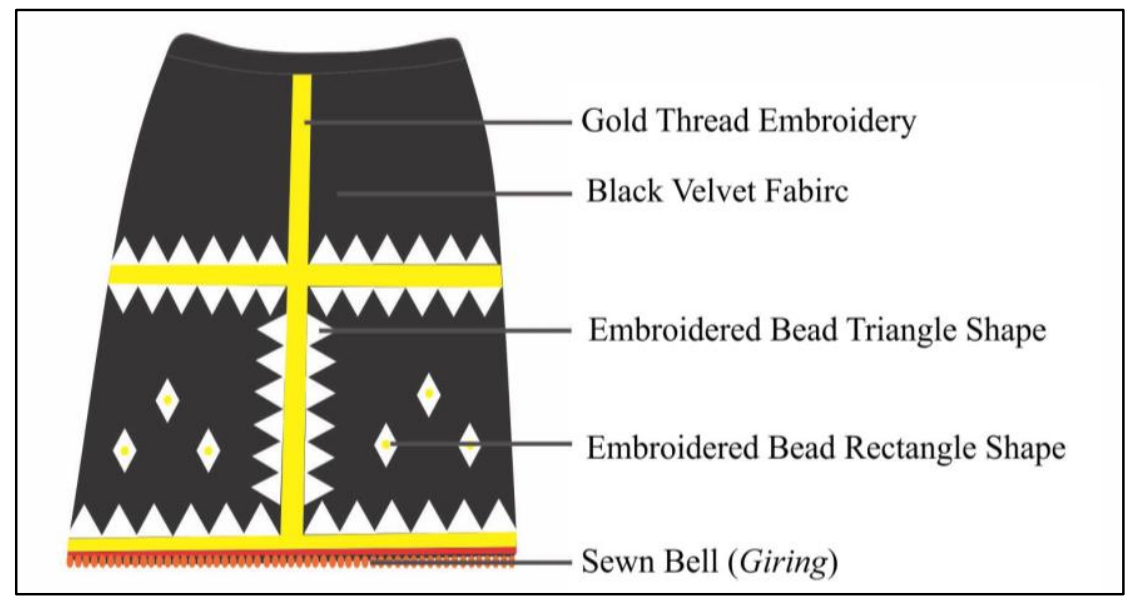

Figure 3: Gonob 
The sinipak for womenfolk is worn together with the gonob made of matching black fabric. The gonob skirt is traditionally knee- length and embellished with thread embroidery and red, yellow and silver beads. A string of bells is placed at the helm of the gonob; any movement would cause the bells to jingle and indirectly announce or signify to the audience the presence of a woman.

The significance of the sinipak costume in the Dusun Tindal culture is deeply entrenched. Every object represents a specific meaning, and these are translated into the embroidery motifs. The bright colour choices are influenced by the ethnic artwork of the Bajau people, another native grouping predominant in the Kota Belud district. According to an informant, the original sinipak costume was black and decorated with betewi buttons, gold color lace and with three layers of vibrant coloured fabrics. This has since evolved to include colour schemes reminiscent of the costumery of the Bajau people, due perhaps to the two cultures being within close proximity to one another and exposed to elements of cultural integration or 'sharing of culture'.

\section{CONCLUSION}

The Dusun Tindal sinipak costume is a cultural heritage that imparts significant pride of association for members of the community. The distinct uniqueness of the sinipak costume, portrayed through its fashion, design and accessories, projects the traditions and artistic skills of the Dusun Tindal of Kota Belud. Further studies on the sinipak from the historical, cultural and economic perspectives are recommended so as to ensure this rich cultural tradition could be documented and preserved for the benefit of future generations.

\section{REFERENCES}

1. Evans, I.H.N. (1953). The Religion of the Tempasuk Dusun of North Borneo. Cambridge: Cambridge University Press.

2. Whitehead, John. (1893). Exploration of Mount Kina Balu, North Borneo (18601899). London: Gurney and Jackson.

\section{Informants}

1. Meso Biddin, 46 years old, Kampung Bangkahak Kota Belud. Maker and keeper of traditional costume sinipak. Interview on 31 ${ }^{\text {st }}$ May 2017.

2. N. Ading Bin Pahau, 57 years old, Kampung Tempasuk Kota Belud. Maker and keeper of traditional costume sinipak. Interview on $4^{\text {th }}$ February 2016. 
3. Rappah Bulleh, 51 years old, Kampung Bangkahak Kota Belud. Maker and keeper of traditional costume sinipak. Interview on 31 ${ }^{\text {st }}$ May 2017.

4. Siap Binti Guladi, 80 years old, Kampung Piasau Kota Belud. Maker and keeper of traditional costume sinipak. Interview on $8^{\text {th }}$ July 2016.

5. Sulia Kubud, 49 years old, Kampung Bangkahak Kota Belud. Maker and keeper of traditional costume sinipak. Interview on 31 st May 2017. 